\title{
Academician Vladimir Evseevich Zuev-Scientist, Teacher, and Organizer
}

\author{
Stanislav D. Tvorogov \\ Institute of Atmospheric Optics \\ Russian Academy of Sciences \\ Tomsk 634055, Russia
}

Jennifer C. Ricklin, FELLOW SPIE

Defense Advanced Research Projects Agency

Advanced Technology Office

3701 Fairfax Drive

Arlington, Virginia 22203-1700

E-mail: jennifer.ricklin@darpa.mil

\author{
Mikael Ciftan \\ Duke University \\ Department of Physics \\ Durham, North Carolina 27708 \\ E-mail: ciftan@arl.aro.army.mil
}

\section{Gennady Matvienko, MEMBER SPIE Vladimir Vladimirovich Zuev \\ Institute of Atmospheric Optics \\ Russian Academy of Sciences \\ Tomsk 634055, Russia}

Academician Vladimir Evseevich Zuev, a member of the Russian Academy of Sciences, quietly passed away from this life on June 6, 2003. Academician Zuev was the founder and permanent director of the Institute of Atmospheric Optics, Siberian Branch of the Russian Academy of Sciences; author of a series of monographs in atmospheric optics; an honorary member of the Optical Society of America; a member of many international scientific councils; and on the editorial boards of a number of scientific journals. In the following brief essay we attempt to provide an outline of his many outstanding scientific achievements and successful efforts in organizing fundamental scientific activities.

Vladimir Evseevich was born on January 29, 1925, in a peasant's family. His homeland was the Siberian village of Malye Goly in Irkutsk oblast (region), located on the Lena River close to Lake Baikal. In 1942 Vladimir Evseevich finished secondary school and started to work as a miner in the region's gold fields. From 1943 to 1946 he served in the Soviet Army participating in military operations against Japan in World War II.

In September 1946, Vladimir Evseevich became a student in the Physics Department of Tomsk State Univer- sity. He published his first article on the spectral analysis of minerals and ores under the guidance of Professor N. A. Prilezhaeva while still a student. He presented his dissertation in 1954 on the subject of "Intermolecular interaction in the quinone-phenol system," and went on to work as an assistant professor of the Department of Experimental Physics at Tomsk State University, where he delivered a complete course of general physics to the students studying there.

The scientific works of Vladimir Evseevich were already being recognized and disseminated during his undergraduate years (1946-1951) in the physics faculty of the Tomsk State University, as well as during his years of graduate study (1951-1954). He chose his early research topics with a view towards applying traditional spectroscopy to geology, and to this end he created a physics laboratory for spectral analysis. The experimental studies conducted there on the intermolecular interaction of complex molecules formed the basis of his doctoral dissertation. Beginning in 1955 Vladimir Evseevich gradually began to focus on what is now called atmospheric optics. This topical area had not been studied in either Tomsk or Siberia before his initiation of these investigations. 


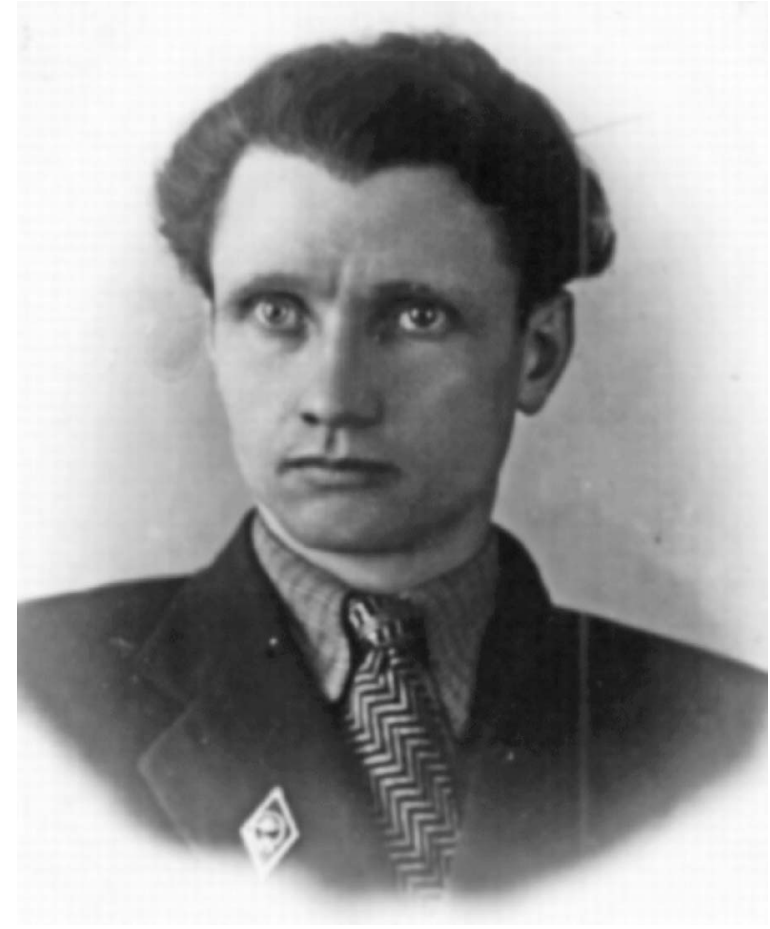

Fig. 1 Acad. Zuev after graduation from Tomsk State University, Tomsk, Russia.

There are many reasons to characterize Vladimir Evseevich as one of the most outstanding organizers of science. Early on, he formulated a creed (here we simply quote from one of his books) that "a continuous chain must be available: an academic idea leading to fundamental and applied investigations, with the use of a unique experimental base; the creation of experimental prototypes of new technology, with small-scale manufacturing production; and the setting up of formal milestones for the realization of such a program." By 1960 he had brought together a group of investigators in his laboratory, now working in the area of atmospheric optics. He then went on to establish an independent laboratory at the Siberian Physical-Technical Institute (1962); the Institute of Atmospheric Optics (1969); and the Special Design Bureau Optica (1972). It should be remembered that these scientific institutions were created to investigate the most fundamental aspects of atmospheric sciences, and eventually provided the foundation for the Tomsk Scientific Center under the aegis of the Russian Academy of Sciences.

A steadfast rule for the scientific work of Vladimir Evseevich was expressed by his phrase "a complex approach." First and foremost, according to him, this rule implied that any problem of atmospheric optics can be formulated as a well-determined physical problem with the appropriate methodology for its solution based on first principles. This implied a careful study of each factor (i.e., molecular absorption, aerosol scattering, turbulence, and later, the effects of nonlinear optics) that affects the atmosphere at optical frequencies, as well as the fact that these must be taken into account as part of an entire assembly of factors in the evolution of the overall characteristics of the atmosphere.

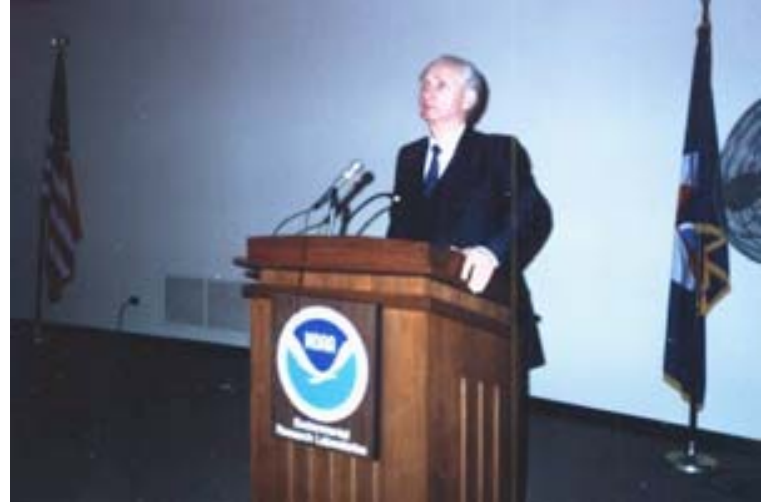

Fig. 2 Acad. Zuev during his 1989 visit to NOAA's Wave Propagation Lab in Boulder, Colorado.

Vladimir Evseevich's tendency was to decrease the number of empirical constants (the existence of these is a special feature of many applications of atmospheric optics), as well as to minimize the number of intuitive postulates necessary to describe the variety of specific atmospheric-optical processes. In particular, Vladimir Evseevich's intuition was illustrated by his wonderful ability to understand the gist of the matter, to see a realistic and efficient method of its solution, and to clearly present the forthcoming result. It therefore follows that the title "The School of Academician V. E. Zuev" is not simply a courteous tribute, but is a real school, and the story of Vladimir Evseevich is, within certain limits, a story about this school. Now we turn our attention to a brief overview of some of the specific scientific achievements of Academician Zuev and his school.

One of Vladimir Evseevich's first significant results on the problem of aerosol optical characteristics was obtained in the late 1950s and early 1960s: the elucidation of the reason for the considerable difference between the results of measurements and the calculation for transparency of artificial fogs. Specially designed experiments were performed in conjunction with reliable theoretical investigations, which were able to sort out the role of an intermediate connecting link-namely, the role of traps for aerosol intake-making it possible to understand that the traps had not been reliably associated with the correct number of particles involved in the aerosols.

In 1965 a series of laboratory experiments were performed resulting in the observation of a new effect, namely the transfer of "contrast brightness" by laser beams at significant optical depths in scattering media. The physics of this phenomenon was rather outstanding, and its understanding created the basis for the production of new, improved navigation devices.

At the present time the Institute of Atmospheric Optics' aerosol program includes an aircraft-based laboratory, the Siberian Lidar Station, and a network of stations for monitoring the components of atmospheric aerosols. This aerosol monitoring program is closely tied to a companion lidar program, offering opportunities for extensive study of the dynamics of the atmospheric boundary layer and the vertical distribution of ozone and aerosols.

It is worthwhile to mention the geophysical results of 


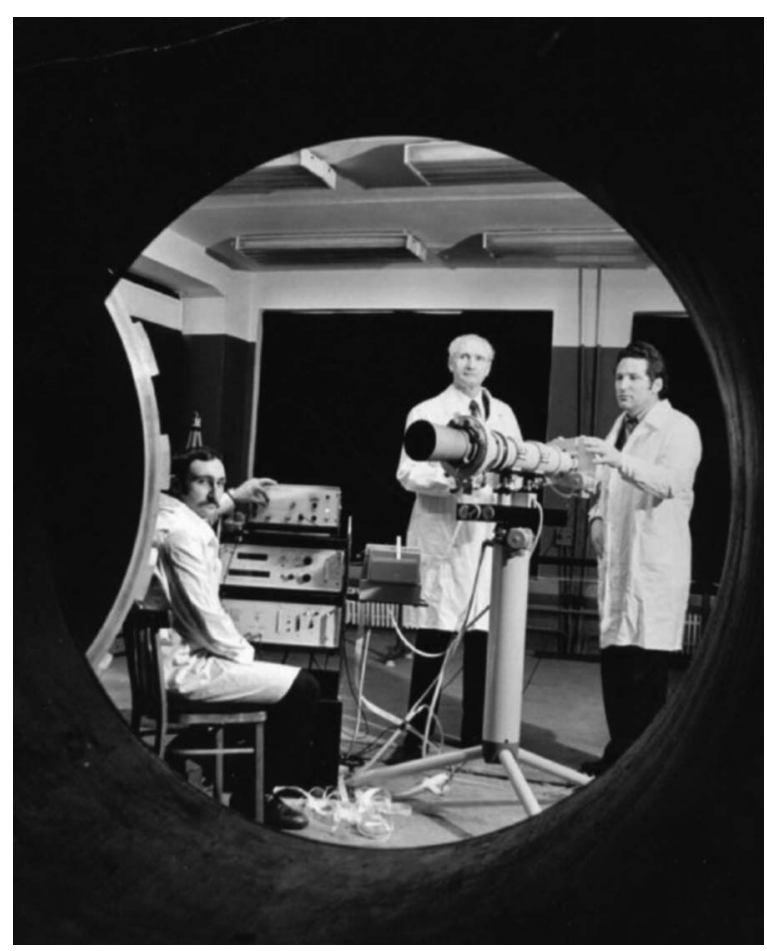

Fig. 3 Acad. Zuev with his colleagues during preparation for an experiment in the Small Aerosol Chamber.

this general program, which include detection of air mass circulations around Lake Baikal and monitoring the consequences of the Mount Pinatubo explosion. Both provide proof of the fact that measurements performed in Tomsk provide background values of aerosol characteristics. This is fundamental for discussing the relationship between natural and anthropogenic factors in the evolution of climate.

Undoubtedly, in Vladimir Evseevich's scientific work the problem of atmospheric laser sounding had a dominant role over many years - from the physical foundations and first experimental techniques, to specific technical devices. Many of the results of this work are presented in his papers, reviews, and monographs.

The enormous amount of information measured in these campaigns caused the scientists to thoroughly automate their physical experiments. The possibilities were studied carefully and many specific problems were solved involving methods of differential absorption, spontaneous Raman scattering, and so on, and prospects for signal detection with the use of high-power laser radiation were shown. Mathematical methods of solving complex inverse problems were used in these problems, and an extensive amount of work was done on the optimal adaptation for specific properties of laser sounding data inversion.

The advent of the laser opened up new avenues in Vladimir Evseevich's scientific work as described in his book Laser Beams in the Atmosphere. He used both laser spectrometers and nonlinear spectroscopic effects in his investigations. In particular, the existence of nonlinear nonresonance molecular absorption of a strong field was proven. Nonlinear optical processes affecting the thermodynamic characteristics of the atmosphere were analyzed,

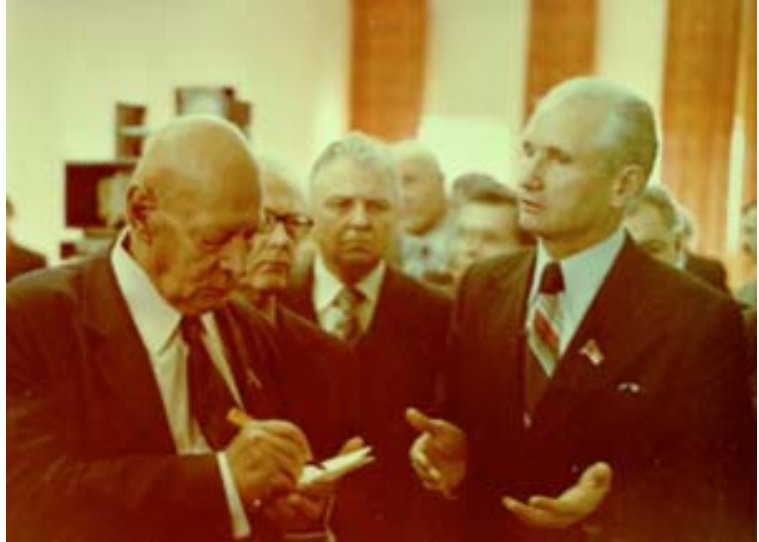

Fig. 4 Guests of honor visiting the Institute for Atmospheric Optics in Tomsk. In front on the left, Academician A. P. Alexandrov, President of the USSR Academy of Sciences; in front on the right, Acad. V. E. Zuev, Director of the Institute of Atmospheric Optics; in the background in the center, E. K. Ligachov, First Secretary of the Tomsk Oblast committee of the USSR Communist Party (June 1977).

for example the combustion of carbon particles in "cold" air, as well as experimental facts and appropriate estimations for the evaporation of water aerosol particles under the influence of a laser. "Cooperation" of the nonlinear effects of laser radiation propagation in the atmosphere was always a difficult problem, and results obtained under the direction of Vladimir Evseevich occupy an important place.

The first work of Vladimir Evseevich in the field of atmospheric optics was the experimental investigation of integrated radiation transmittance for an absolute blackbody in the atmospheric boundary layer. It is not unexpected that this immediately raises a question concerning interpretation of the data for all related measurements. A critical analysis of absorption band models demonstrated the inaccuracy of an argument popular at that time, the "square root law," and the partly heuristic method for describing the absorption function of the heterogeneous part was strictly proven.

In his later years Vladimir Evseevich initiated a con-

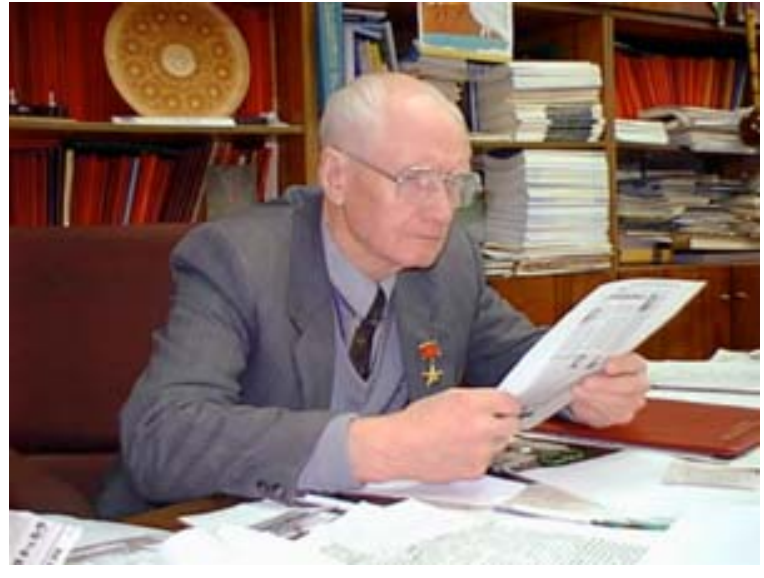

Fig. 5 Acad. Zuev at work in his study, mid-1990s. 
tinuation of this program using the analytical rules of the Dirichlet series mathematical theory. This formed, in effect, a renaissance of several precomputer era ideas for the solution of problems related with integrated absorption, but now with the help of the computer's many potentials. This was a step forward in solving the problem of decreasing the radiation block of climatic models, while retaining the necessary accuracy for forecasting.

During his active role in solving these problems of atmospheric spectroscopy, the statements formulated by Vladimir Evseevich were both extensive and fundamental. It is particularly remarkable that the results of this program are also of practical significance and fall outside the scope of atmospheric spectroscopy. Some examples are the study of highly-excited vibration-rotation molecular spectra of atmospheric gases, evidence of the existence of a local resonance of a definite type, a detailed analysis of shifts in the pressure line centers, and so forth.

New versions of the solution to the inverse spectroscopic problem were developed, which are necessary for study of the vibrational-rotational spectrum of molecules. There are many convincing examples of theoretical corrections to experimental measurements, and also supplements to the spectroscopic data. It should be particularly emphasized that spectroscopy was considered not as "a supplier" of numbers for problems in atmospheric optics, but as a prerequisite to a new level of understanding for the solution of these problems. In due time, Vladimir Evseevich proposed a well-founded program for the investigation of continuous absorption by water vapor. This program included a theoretical part and a major experimental component; all of this taken together offered a clearer view and deeper understanding of the physical basis for this problem.

During his lifetime Vladimir Evseevich wrote over 30 monographs and 700 scientific articles. Vladimir Evseevich was also the initiator, editor, and co-author of an encyclopedic series of monographs on modern problems in atmospheric optics (nine volumes total), which became an important landmark in his creative work.

An important part of Vladimir Evseevich's life was the development of the Tomsk Academgorodok (academic city) with its social sphere carefully developed by him from 1975 to 1992, as well as the Tomsk Scientific Center of the Siberian branch of the Russian Academy of Sciences. At present the scientific center includes five institutes, two of them-the Institute of Atmospheric Optics and the Institute of Highcurrent Electronics-being the largest of their kind in Russia.

Vladimir Evseevich's life in Tomsk was interrupted during the years 1991-1996 by his Moscow period, when he held an important post as one of the leaders of the Russian Academy of Sciences. He headed the Department of Oceanology, Atmospheric Physics, and Geography of the Russian Academy of Science, making efforts to help the new Russia enter into international scientific programs. For this period of his life he received the "Compass," an international award presented by the American Society of Marine Technologies.

Vladimir Evseevich was elected a member of the Soviet parliament - the Supreme Soviet of the USSR - three times, so very often he had to be away from Tomsk. How- ever, he never forgot about his favorite creation-the Institute of Atmospheric Optics. After he resigned in 1997 he became its honorary director. Even in that period of his life Vladimir Evseevich remained active: he founded and headed the International Research Center for Physics of the Environment and Ecology, and served as its director until his death.

Throughout his life, Vladimir Evseevich Zuev was an indispensable and active participant in numerous scientific symposia on the subjects of atmospheric physics, atmospheric optics, laser sounding, and related topics. He organized the International Laser Radar Conference, one of the first symposia on this subject, held in Tomsk in 1990. He was also a founder of the International Symposium on High Resolution Spectroscopy, which continues up to the present. The workshop "In Memory of Academician Vladimir E. Zuev: A Legacy in Atmospheric Optics," held in conjunction with the 2004 SPIE Annual Meeting and dedicated to this great man's memory, provided an occasion to recall his outstanding achievements in the development of international scientific cooperation.

We therefore dedicate this special section of Optical Engineering to the memory of Academician Vladimir Evseevich Zuev, in honor of his many contributions to science over his long and productive life.

Stanislav D. Tvorogov: Biography and photograph not available.

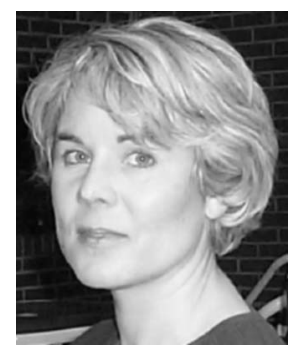

Jennifer C. Ricklin received her $\mathrm{PhD}$ in electrical engineering from the Johns Hopkins University, MS in electrical engineering from New Mexico State University, and BS in physics from Sam Houston State University. Dr. Ricklin began her career at the Atmospheric Sciences Laboratory in White Sands Missile Range, New Mexico, in 1983 and transferred to the Army Research Laboratory in Adelphi, Maryland, in 1996. Currently she is a program manager with the Advanced Technology Office of the Defense Advanced Research Projects Agency. Her research over the years has encompassed the topics of laser beam propagation in atmospheric turbulence, imaging through atmospheric turbulence, optical turbulence modeling, laser beam diffraction, optical coherence properties in random media, and simulation and adaptive correction of atmospheric-induced distortions. Dr. Ricklin has chaired or cochaired a number of international conferences, and has served as associate editor for Optical Engineering since 1998. She is a fellow of SPIE.

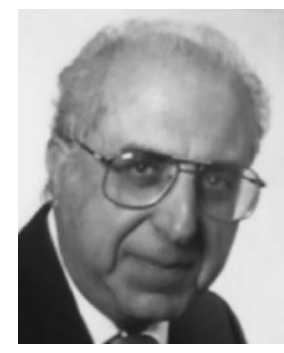

Mikael Ciftan received his BSc degree in engineering summa cum laude from the American University in Istanbul and his MSc degree in experimental physics from the Massachusetts Institute of Technology (MIT) doing the first all-optical highestresolution measurement of the isotope shift in the nuclear hyperfine structure of thallium atoms. Based on this work, he joined the race to be the first to produce laser action, which he missed by a few weeks. His laser was said to be the second in the world and had fifteen times lower threshold than Mainman's first, because Ciftan had made use of principles of optics. Ciftan was able to measure for the first time the longitudinal modes of the ruby laser using his MIT spectrometer. Later he used concepts of spin-lattice relaxation dynamics to introduce strong feedback via a corner cube in 
the laser cavity to eliminate chaotic spiking oscillations demonstrating for the first time chaos control before that subject was later formulated and formalized. He also produced the first highest power (10 W cw) GaAs laser by developing and using new controlled diffusion techniques for the $p$-n junction/cavity quality control. He then pursued further theoretical physics subjects, developing new mathematical physics techniques relevant to a wide range of applications of many-body theories, and received his PhD degree in theoretical physics from Duke University. He became an adjunct full professor of physics at Duke University while joining the Army Research Office (ARO) in 1970 as the program manager of theoretical physics, condensed matter physics and nonlinear optics. He selected and supported basic research projects which he successfully transitioned into diverse technologies for civilian as well as Army/DoD specific applications. He retired from ARO in January 2005 and is continuing to pursue his own research interests. He is a fellow of the Optical Society of America, has published extensively in several areas of the physical, engineering, and mathematical sciences, and holds a basic patent on the laser and a medical device.

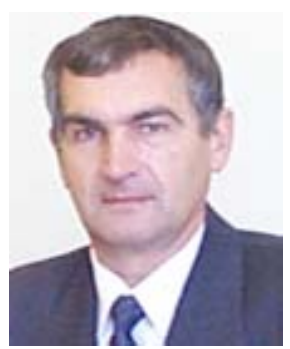

Gennady Matvienko received the diploma in physics from the Tomsk State University, Tomsk, the Soviet Union, in 1970. From 1970 to 1973 he worked in the field of laser sounding at the Institute of Atmospheric Optics of the Siberian Branch of the USSR Academy of Sciences. He then continued his education from 1973 to 1975 in the postgraduate course of the Tomsk State University, Tomsk, USSR. In late 1975 he earned his $\mathrm{PhD}$ degree in optics on the subject "Laser sounding of wind velocity and direction." In 1976 he continued his work at the Institute of Atmospheric Optics in the field of lidar measurements of profiles of meteorological values. In 1988 he defended his doctoral thesis and has been a full professor and head of the Laboratory of Optical Sounding of the Atmosphere. Since 1998 he has been the director of the Institute of Atmospheric Optics, Siberian Branch of the Russian Academy of Sciences. His current research interests are in the development of laser sounding techniques of the atmosphere and underlying surfaces, and the interaction of femtosecond laser radiation with the atmosphere. He has published more than 50 journal papers, five monographs, and holds five patents. Prof. Matvienko is a member of the Optical Society of America (OSA) and the International Society for Optical Engineering (SPIE).

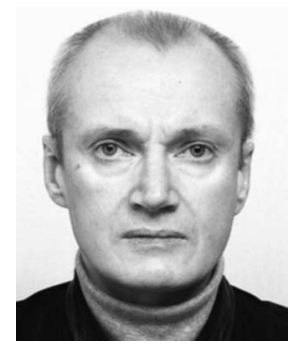

Vladimir Vladimirovich Zuev is a wellknown specialist in laser sensing and physics of the middle atmosphere, a corresponding member of the Russian Academy of Sciences, and a professor. He is the author and co-author of more than 300 scientific publications, including nine monographs. After graduation from the physical faculty of Tomsk State University, in 1978 he began to work in the Institute of Atmospheric Optics, Siberian Branch, Russian Academy of Sciences (RAS). In 1986 he defended his candidate dissertation, and in 1992 his doctor dissertation. In 1997 he was given a rank of professor and elected as a corresponding member of RAS. Since 1986, he has been head of the Laboratory of Atmospheric Remote Spectroscopy in Institute of Atmospheric Optics. Under his leadership, a unique multichannel experimental complex Siberian Lidar Station with base receiving 2.2-m telescope was created, which has allowed remote performance of continuous complex stratospheric studies for more than 15 years. $\mathrm{He}$ constantly performs active work with under- and post-graduate students. Among his students are 5 doctors of sciences and 19 candidates of sciences. 